\title{
Paying Attention: Early Modern Science Beyond Genealogy
}

\author{
Carla Nappi \\ University of British Columbia \\ carla.nappi@ubc.ca
}

\begin{abstract}
To move away from histories of early modern science that are shaped by the notion of a Scientific Revolution, the essay proposes a historiographical methodology that moves away from genealogy and toward juxtaposition as a principle of storytelling. It briefly discusses the study of sound in early modern Manchu texts as an example of this \#hashtag (or juxtapositional) history.
\end{abstract}

\section{Keywords}

history - early modern - Manchu - genealogy - sound - science - context

\section{Introduction}

Paying attention is a kind of world creation. It is a way of moving through the world and activating parts of our environment in the process, identifying and creating objects and locations, and - through the movement of our attention-relating them to each other as part of a cohesive and ephemeral fabric.

Paying attention is also part of the craft of the historian. The way we pay attention shapes the way we tell stories. It determines what a document becomes in our hands, and how we relate it to other objects and stories, and to each other. These essays are intended to collectively offer focused attention to a notion, and in attending together, to undo that notion in order to make space to build something else in its place ... or perhaps in another place altogether. 
That notion is a singular European origin of modern science in the sixteenth and seventeenth centuries, a modernizing "Scientific Revolution." It is clear that this notion needs our attention. Even as early modernists perform a collective moving-away from the notion of a Scientific Revolution, the assumption (under various rubrics and in various guises) still structures much of what binds the history of science together as a common field of inquiry.

When we consistently pay attention to documents and events in relation to a genealogical story (or stories) about the history of science, it constrains the kinds of stories we can tell. Our field is still defined, explicitly or not, by a sense of the genealogy of our object. And the Scientific Revolution-as a germinal period located in early modernity, and located in European early modernity specifically — is a key node in that genealogy. Moving away from a mode of organizing our collective inquiry with reference to a "Scientific Revolution" would thus involve moving away from genealogy as the basis for organizing our field. (At least, it would involve moving away from a straightforward model of genealogy.)

This think-piece will consider what it might look like to do so, by orienting our attention to the art of paying attention as part of our craft and to a series of questions that we might dwell in for a while to see what comes. What might a historiography of early modern science that was not a genealogy unfolding from a Scientific Revolution look like? What would or could be left as an organizing principle after we take (that) genealogy away? What other forms of paying attention are available for telling stories about the history of early modern science? Why does any of this matter?

\section{Before and After}

For a historian, the act of paying attention is a way of making time, or at least a way of making the past. We tend to do this by identifying nodes, ordering them in terms of before and after, and creating causal stories from that ordering. I will be using the term "genealogy" as a shorthand to refer to this act. As a historian of science, it is hard to imagine how one might escape from a genealogical approach in constructing a history. To create a story in time- to create a path in time for readers to follow-is to create a genealogy. Even radical approaches to making a nonlinear history or archaeology of science tend to do this. This poses a major methodological problem: if our craft as historians still relies on genealogy at the core of our storytelling practices, what would it look like to create genealogies of the history of early modern science that did not take the Scientific Revolution as a central node? (Would it even be possible to 
do so?) One way to imagine ourselves toward a different kind of history of early modern science is to imagine a history that did not—or that did not necessarily or primarily — proceed via genealogy as a core aspect of its methodological approach.

If genealogy is a way of treating time as a sort of space, then it is also a way of thinking about and producing locality in time. When we think about the global in the history of science, we often think about the problem of localities and their connections: identifying them, characterizing them, mapping them, connecting them. How might we map early modern science without producing the Scientific Revolution as a locality? I would like to approach the problem of locality, its emergence, and its significance for the historiography of science by opening up our discussion of what, where, and how "locality" (as an object and a process) emerges. We might do this is by thinking about what we are doing when we encounter a document or an archive in terms of a particular way of paying attention: observing a portrait.

Consider how we encounter an imaged portrait: we take in the totality of the face and then move to focus on its parts in sequence. Maybe we look at the hair, then the eyes, then back to the face, then the mouth-it happens quickly and the process is probably different for each of us. A portrait is a kind of space, and by moving through a portrait we help create and activate that space. We experience, recognize, and understand a portrait by moving across its parts and totality. As we perceptually move across a portrait, this movement simultaneously creates localities from points of perceptual rest and reorientation, creates relationships among those localities, and from this movement ultimately emerges a global understanding and impression of the work as a whole. In other words, localities do not precede movement through and across them: the phenomenon of locality is created by the act of movement and the relations that this movement engenders. This is true for temporal locality as well as spatial. The temporal locality of the Scientific Revolution, then, is produced as we move through our documentary and material archives and create relationships among them to tell stories about the history of science. To create a different kind of locality, we need to move through our archives differently.

Moving away from stories about the history of early modern science that are grounded in genealogies of science involves moving away from stories about the history of science that prioritize or invoke origins. This is another place where I find it helpful to think about portraiture. The kind of work a portrait does is not necessarily bounded to its original referent: we can experience and understand a portrait even if we are not relating the experience of the image (be that image visual, textual, or otherwise) to a knowledge of or concern with the source of that image. The portrait can generate a sense of character or 
personality without that character or personality necessarily referring to the individual on which the portrait was originally based: in fact, rather than the portrait acting as a representation of something or someone out-there-in-theworld, the portrait arguably generates the self that it is meant to correspond to. I would suggest that moving away from stories about the history of science that are concerned with origins-i.e., genealogical stories-is an important way to move away from stories grounded in a Scientific Revolution. Doing this calls for paying attention to documents in a different way.

\section{Next to}

Eschewing genealogical accounts in favor of treating an archive as a kind of portrait can help make sense of the documentary traces of the history of early modern science that otherwise might escape our attention. The fragmentary history of Manchu science and medicine offers one example. Through the seventeenth and eighteenth centuries, a good deal of material on scientific and medical topics was composed by Jesuit missionaries, often in conjunction with Manchu-literate associates even when those associates were not credited by name. Many of those materials survive, but the extant body of these Manchu documents is spread across archives and book collections from St. Petersburg to Mongolia to London to Tokyo. Many of these documents are bereft of the kind of paratextual material that would tell us much about the authorship and genesis of these works. Though it is possible to generate a partial picture of the production of these materials by looking through the letters, diaries, and other records of Jesuits who helped pen them, along with court records and the Manchu texts themselves, it is very difficult to have a sense of how (and how widely) they were used and read. Put simply, many of these materials do not lend themselves to the kinds of analyses that would result in answers to many of the questions typical of the (global?) historiography of early modern science and medicine. We can, however, use them in another way, by paying attention to these documents as elements of a portrait or landscape.

I have been using this multi-sited Manchu-language archive of materials as the basis for attempting to think my way toward an approach to the history of science that differs from the model of global science that charts knowledge circulation among localities. That (circulation-based) model tends to assume a historical context that provides the ground from which stories of the circulation of knowledge, people, objects, texts, and ideas emerge. "Context" here is often what we are talking about when we imagine a rich historical accounting of a phenomenon: it involves characterizing the people, places, and ideas that 
populate a space of encounter, and mapping their relationships in a way that provides the basis for constructing narratives about the past: $\mathrm{X}$ caused $\mathrm{Y}$ to happen, and we know this because we can show some sort of clear relationship between $\mathrm{X}$ and Y. Historically-significant relationships, here, tend to be those relationships that can be linked through documentary chains of evidence, and which can therefore support historical claims about causation, with chains of causation forming the architecture of historical accounts that emerge from this evidence. "Historical context" is thus a way of signaling this rich space of possible causal relations, a space that emerges from a very particular kind of documentary archive. A historical explanation, in these terms, is a statement rooted in claims about causation. Network-based analyses of global science, technology, and medicine tend to follow this trend. And this is significant because they also tend to characterize the bulk of extant historiography of global science, technology, and medicine.

It has become a commonplace to acknowledge that knowledge is made in circulation, and that circulation itself is a kind of locality. Still, circulation-oriented histories of global science, technology, and medicine tend to follow the context/causation model of historiographical explanation described above. Even when the circulation being charted is an "open flow" characterized by "mutations and reconfigurations" of that which is being circulated (in the words of an important, cogent, and oft-cited recent piece on circulation in the history of science), ${ }^{1}$ circulation "occurs within bounded spaces." ${ }^{2}$ And those spaces are not just geographical: they also include the spaces of language, of geo-politics and the state, of concepts; in stories about the circulation of entities, something needs to remain stable and bounded for other things to move, and that "something" can be a language (French, Chinese, Tagalog, Manchu, etc.), an assumed geo-political entity ("China," the West, France), or (as in the kinds of histories of and with natural objects and materia medica that I spend a lot of time with) an object (ginseng, fur, clay, iron) or a term. As a result, even while they aim to complicate and undo the kinds of binaries that have long characterized the history of science in a global frame (center/periphery, metropolitan science/colonial science, production/consumption), circulation histories simultaneously reify the apparent stability and coherence of other entities that some of us would like to problematize. Even if we put aside that issue for the moment, though, there is another way that circulation-based histories can be limiting. A circulation-based history is fundamentally a history

1 Kapil Raj, "Beyond Postcolonialism ... And Postpositivism: Circulation and the Global History of Science," Isis 104, no. 2 (June 2013): 337-347. The quotes above occur on 344.

2 Raj, "Beyond Postcolonialism," 345. 
about tracing causal links: in order for a circulation (an itinerary, a movement) to be a locality, one has to be able to map that locality, which means tracing clear connections between agents whose relationships create circulatory pathways.

But what if one's sources do not lend themselves to the tracing of such connections? And what if we attempted to pay attention to those sources in a way that made that absence into an opportunity rather than a failure? What if, inspired by the kinds of materials I briefly introduced above, we imagined another way of generating (and then relating) stories of and from a multi-sited and global history of science, one that was not necessarily based on a model of causal relationships emerging from a richly documented historical context, but was instead based on a practice inspired by generating and linking localities from the process of moving across single and multiple pages? What if we supplemented existing kinds of circulation-based stories with others that were based not on a method of producing a documentary archive according to a vertically-oriented sedimentary model of time (digging and probing down into a documentary archive, like a paleontologist, to show causal links over different points of time), but instead approached our documents in the spirit of pattern-recognition, juxtaposing materials on the same spatial plane without demanding that they support a set of richly-contextualized causal explanations? What if, in other words, we considered the act of juxtaposition (and associated kinds of attention-paying) as a historical practice? What might this kind of practice look like?

The method that I have been using to generate stories with the Manchu documents I described above is something I have taken to call juxtapositional history, or "\#hashtag history." Put simply, this is a method of reading historical documents (especially fragmentary, de-contextualized historical documents) that functions sort of like a \#hashtag does in the Twitterverse. Twitter users function as independent points or nodes in a cloud. Individual tweets are sent out into that cloud, and unless a reader happens to subscribe to the Twitter feed of an individual user (or unless a user whose feed they do subscribe to retweets a comment from a user they do not subscribe to), there is no obvious way of linking one Tweet to another. What Twitter users have developed as a way to produce conversations in this medium (especially in the absence of a kind of context that is characterized by directly-linkable causal connections between documentary traces, as described above)—what they have developed as a means of paying attention in this medium-is a system of hashtags represented by the \# symbol. By placing a hashtag in front of a term, a Twitter user links her use of that term with that of other users who have done the same. A 
hashtag thus functions as a binding device, relating otherwise-disparate nodes into a common network.

The kind of history that emerges from this sensibility is not a history of documents. It is a history with documents. It attempts to juxtapose texts to produce an archive that is held together not by physical paper or binding but with the historical equivalent of a hashtag, a common conceptual thread or theme. It is a way of reading texts that challenges an approach based on deep context, effectively a kind of surfer's approach to the global history of science in general, and to Manchu documents in particular: rather than rooting these works in contextual soil, we are riding the thematic and conceptual waves that emerge and recede from a rather fluid landscape. Hashtag history as practiced in this way is an extension and rethinking of a method of history-throughjuxtaposition that elsewhere I have referred to in terms of constellation, curation, and DJ'ing. It is a refiguring, in a way, of a classic move of comparative history (a kind of historiography that has featured prominently, explicitly or implicitly, in attempts to craft a global history of science): by putting unlikely fellows next to each other, we might see each of them in new ways.

How and why might this be significant for the global history of early modern science, generally speaking? Thinking in terms of juxtapositional history is a way of thinking anew about, and generating different forms of, space and locality in the global history of science. We often tend to treat space (and by extension, place and locality) as a physical or geographical container for stuff. We might instead, following Alfred North Whitehead, think about space as a set of possible relations, a collection of non-extensional points that can be related to one another. ${ }^{3}$ Space, in these terms, is thus defined not by geo-physical locality, but as a condition of actual and possible relations among its constituents. The hashtag comes into this picture of space as a tool for mapping relations. The hashtag creates proximity that is not defined by, and does not depend on, geo-spatial location. The kind of "locality" (or, way of being "local"), according to this way of conceptualizing space, does not have to be rooted in broader preconceived spatio-temporal categories.

If we think about space in this way, how might this help us rethink locality, and reframe the conversation about global histories of science? If paying attention to documents creates relations among them, and relations are what constitute a given space, then we can map those relations onto different kinds

3 On this way of thinking about Whitehead thinking about space, see William E. Connolly, The Fragility of Things: Self-Organizing Processes, Neoliberal Fantasies, and Democratic Activism (Chapel Hill, 2013), Ch. 4. 
of (and differently sized) units that ground different kinds of stories that can simultaneously coexist and inform one another. We might consider the space of a page, then, locating instruments of globality and the production of scientific knowledge as it emerges from relations on that textual unit: how might this turn our attention to the ways that the individual elements that most readily emerge at that level of observation (prepositions, punctuation, spacing of letters, crossings-out and erasures) shape our stories of scientific production? We might consider the space of an image: how does a particular way of depicting a nose or the invocation of a symbol generate a kind of ground or field, and what kinds of questions does that conception of space let us ask? We might consider the space of certain kinds of likeness: how is a particular kind of space generated by using a particular method of relating objects or terms to one another, of producing likeness or equivalence? We might consider, as I do below, the space of translation and its media: how do the texts of translators (including Manchu-language texts on the interaction of human and other bodies) produce particular ways of understanding and experience that depend on but ultimately transcend language? What all of these have in common is a way of creating a kind of historical space, and an archive of materials that generates that space, without prioritizing "context"—or at least by rethinking what "context" might mean and look like-and without invoking genealogies of science. ${ }^{4}$

So what might be an example of paying this kind of attention? And what ways of telling stories otherwise might this open up?

\section{Voicing Early Modern Materialities}

I have been interested, recently, in doing a history of science of and with objects that does not take the category and concept of "material object" as a trans-historical given and does not assume the coherence and solidity of an object when understood in a multi-sited, global frame. I am trying to do this by historicizing notions of materiality, and trying to understand how materiality (conceptualized as perceptive experience of bodies as they come into relationships with objects) is produced by and emergent from my historical documents,

4 This is not a new thing to want to do: we might turn to the efforts of, for example, Annemarie Mol and John Law in arguing that the social performs several "kinds of space" that include fluid topologies as well as regions and networks. See Annemarie Mol and John Law, "Regions, Networks and Fluids: Anaemia and Social Topology," Social Studies of Science 24, no. 4 (Nov. 1994): 641-671. 
rather than reading materiality into my documents. I have been doing this by paying attention to them in a way that activates a kind of hashtag-approach to my materials.

In one case, I am trying to understand how sonic experience emerges out of Manchu text by using \#languaged-sound (sound as rendered into human language) as a binding element to bring together and juxtapose several different kinds of Manchu texts that are not often put into dialogue, including dictionaries, anatomical treatises, poems, and texts on the nature and qualities of drugs. By doing this, I create a kind of sonic space, an embodied Manchu soundscape, that allows me to read these texts as tools for voicing the material world.

One kind of documentary material in which \#languaged-sound appears is lexicographical. Here, we find Qing dictionaries like the pentaglot [Yuzhi] Wuti Qingwenjian. ${ }^{5}$ This book is full of many thousands of terms that are classified, ordered, and translated in thirty-two main categories. Each category serves as a miscellany made of objects that explode and multiply on the page, with any given Manchu entity finding partners in Tibetan, Mongolian, Turkic, and Chinese scripts. The categories range from The Heavens to Insects, with additional entries appended at the end of the dictionary. An entire section of the dictionary is devoted to the sounds that people make and hear, ${ }^{6}$ containing nearly three-hundred sound-related terms, most of which are onomatopoeias: people bodor'ed as they mumbled through their teeth or keser'ed as they used those teeth to chew hard objects; hearts tuk-tuk'ed while they pounded; fire huung'ed to life; birds took flight suddenly with a kior; firecrackers exploded with a chur char; porcelain fell with a hitalar; rice sar sir'ed as it was washed; and animals fasak'ed as they suddenly emerged from hiding. ${ }^{7}$ Here, onomatopoeias represent the sonic natural world made corporeal. Collectively they produce a soundscape of natural history that is meant to be voiced by people: these terms only become meaningful when acted out, pronounced, produced and re-materialized with the body. And importantly, sounds in this context are mediators (or ambassadors) that create relationships: between people and objects, between individual speakers/listeners and collectivities, and between words and materials. Sounds bridge the knower and the known. Importantly,

5 [Yuzhi] Wuti Qingwenjian (Qing Pentaglot) (Beijing, 1957), 3 vol.

6 See [Yuzhi] Wuti Qingwenjian (Qing Pentaglot) (Beijing, 1957), vol. 2, 1875-1950.

7 See Carla Nappi, "A Page at the Orchestra," in Wendy Doniger, Peter Galison, and Susan Neiman, eds., What Reason Promises: Essays on Reason, Nature and History (Berlin, 2016), 221-227. I have created a little imagined soundscape using many of these, and you can find and listen to it here: http://carlanappi.com/2014/01/o7/kunggur-kanggar-a-landscape-of-manchuonomatopoeias/ 
these sounds can also be translated: the sound of a grasshopper's wings in Manchu could also be rendered in Tibetan, Mongolian, and other Qing languages; and though it would be the same sound (the same sonic object), that sound would sound different in another language.

If we pay attention to these materials from the perspective of \#languagedsound, we can put them into dialogue with other kinds of \#languaged-sound that we might not otherwise relate them to. An example of this can be found in anatomical texts like the Dergici toktobuha ge ti ciowan lu bithe (Imperially Commissioned Complete Record of the Whole Body, or simply, ManchuAnatomy), a treatise on anatomy commissioned by the Kangxi Emperor and written between 1710 and 1715 . The text is organized by regions of the body, beginning with the head and eventually making its way through the internal organs. In its various sections, a kind of Manchu soundscape emerges from descriptions of parts of the body. These include accounts of the sounds produced by the shapes of mouth and throat anatomy and their variations, especially in discussions of the windpipe, esophagus, and tongue. Together, these anatomical descriptions produce an account of the sounds of the human body that privilege the materiality of the breath (or, sukdun), of the body's movements and vibrations, and of the fleshy and bony architecture of the human body as a sonic instrument. They also render the sounds of the body in human language, though here the language is descriptive rather than onomatopoetic.

Other instruments enable sonic production by bodies, and by paying attention to those instruments, we can bring other kinds of texts into conversation with lexicography and anatomy: texts about Manchu script, for example, or poetic texts that use sonic rhythm and rhyme to generate and translate bodily experience. In the interest of economy I am keeping this brief, but, briefly put, the kinds of texts that are brought into the conversation if we operate in this hashtag-historiographical mode include Manchu poems and verse texts that otherwise would bear no strictly-contextual relation to the dictionaries and anatomical texts described above.

Taken together, these individual textual points create a space of \#languagedsound (and concomitantly, an archive of \#languaged-sound) that does not emerge from a single geo-spatial or geo-political context, and thus this archive does not allow us to ask or answer certain kinds of historical questions. We cannot answer many questions, for example, about the conditions of production or consumption of some of these texts, about their influence, or about the ways that they transformed knowledge-making, all of which are typical kinds of queries brought to the archives that usually characterize global histories of science. Instead, we are able to ask different kinds of questions and tell different kinds of stories about relationships of texts, bodies, and experience as they 
emerge from translation in the seventeenth and eighteenth centuries. These stories, based on juxtaposing documents and binding them in non-contextual (or at least differently-contextualized) and non-genealogically-oriented ways, can then transform what we see when we look at these same documents in other kinds of stories that emerge from locating these documents in other kinds of space: in more traditionally-contextualized stories about knowledge production at the Qing court, for example, or in histories of the circulation of texts in early modern Eurasia. For me, analyzing Manchu texts in the way I described above made me ask questions of the material that I would not have thought to ask otherwise. What is a "sound," and what is its relationship to language? What is the relationship between language and voice in Manchu texts? How are somatic experiences (like sounds) translated? What kind of historical object is the Manchu voice, in particular? How do the relationships between objects, human bodies, and words produce materiality, at least as manifest in historical documents? Different sorts of historical objects emerge from this kind of juxtapositional practice than might otherwise emerge from a more contextually-rooted or genealogical approach to the history of, for example, "medicine" in Qing texts. Objecthood, here, is co-produced by words, bones, breath, sounds, flowers, rhythm and rhyme, all at least potentially in translation.

\section{Storytelling}

So, why might this matter? Why would we want to do this? What is wrong with the way we have been doing and thinking about global histories of science? Well, one answer to this is that, for you, maybe this is not worth doing. Maybe you are satisfied with the kinds of stories that we have been generating in trying to produce a more multi-sited and polyvocal historiography of science, and maybe taking geo-spatial and geo-political "context" and genealogy out of a story makes that story into something that is simply not history anymore. If that is the case, then that is fine, and this paper probably is not for you. But if you are, as I am, looking for ways to move beyond the kinds of spatiality and locality generated by "global" histories of science and the kinds of objects ("China," ginseng, the West, the "Scientific Revolution") that are produced by it, if you are interested in experimenting with forms of storytelling that might emerge from new ways of building historical space, then perhaps this thought experiment is a way to start to think toward an otherwise.

What might it come to mean, if we understand locality in the history of sciences in this way, to "[think] globally about the history of modern science"? 
Well, if we allow ourselves this degree of flexibility in terms of conceiving kinds of space, then "global" as a useful analytic category might drop out of the picture. Our stories instead become ways of thinking in terms of multiple, overlapping kinds of locality in time and space. Because we are not telling stories in time according to a model of genealogy, the groping toward an origin point or genealogical node (i.e., the Scientific Revolution) also drops out. What we are doing instead is, in a sense, what we have always been doing: transforming our archives and cases and contexts into a constellation of stories that were always meant to be layered onto one another, to be ephemeral, to come into and out of being and, ideally, to help others tell equally ephemeral stories of their own. We re-commit to the foundational principle that all of our stories, in order to constitute part of a common historiography, can only ever be meaningful as part of a plurality of other stories. Not only can no single history or genealogy of early modern science ever be complete or comprehensive; taken on its own, it can only ever be fragmentary. What I am proposing here is a reorientation that takes that fragmentariness as a strength and a raw material to work with, rather than seeing it as a necessary drawback. It places terms or sounds or texts or ideas next to each other and pays attention to see what might emerge in-between. It does not assume the existence of historical objects or agents before the juxtapositional encounter from which historical objecthood and agency emerge as processes. It is not interested in origins. It looks, and it listens. It pays attention. If we maintain our commitment to genealogically-defined histories of early modern science that treat localities and objects as historical entities that persist in time and space, it is difficult to imagine how we will ever move on from a Scientific Revolution-centered approach to work in the field, or how we will manage to take a "global" approach that does more than turn the history of science into a subset of area studies. We will have to have the courage to break things in order to create something new with the fragments that are left. 